\title{
Zinco, chumbo e cádmio em plantas de arroz (Oryza Sativa L.) cultivadas em solo após adição de resíduo siderúrgico
}

\author{
Zinc, lead and cadmium influence in rice plants (Oryza Sativa L.) cultivated in soil with addition \\ of siderurgical residue
}

\author{
André Fernão Martins de Andrade ${ }^{\mathrm{I}}$ Nelson Moura Brasil do Amaral Sobrinho" \\ Márcio Osvaldo Lima Magalhães" Vinicius Sampaio do Nascimento" ${ }^{\mathrm{II}}$ Nelson Mazur $^{\mathrm{II}}$
}

\section{RESUMO}

Os efeitos da aplicação de resíduo siderúrgico, proveniente da concentração de zinco em lama de altos-fornos siderúrgicos, como fonte de zinco para plantas de arroz (Oryza sativa L.) BRS Curinga e a toxicidade devida ao cádmio e ao chumbo no resíduo, foram estudados em experimento de casa de vegetação. O material de solo usado foi proveniente do horizonte $A$ e $B$ de um Latossolo Vermelho-Amarelo e do horizonte A de um Neossolo Flúvico, coletados no município de Pinheiral, Estado do Rio de Janeiro. Foram aplicadas quatro doses de resíduo $\left(94 ; 281 ; 844\right.$ e $\left.2531 \mathrm{~kg} \mathrm{ha}^{-1}\right)$. Foi determinado o teor de zinco, cádmio e chumbo na raiz e na parte aérea das plantas de arroz. As plantas crescidas no horizonte A do Neossolo Flúvico apresentaram a maior produção de matéria seca e a maior acumulação de zinco e a menor de cádmio. As plantas de arroz desenvolvidas no horizonte $B$ do Latossolo apresentaram a menor produção de matéria seca, menor acumulação de zinco e a maior de chumbo, enquanto que as cultivadas no horizonte $A$ do Latossolo apresentaram a mais elevada produção de matéria seca dos três substratos utilizados. O zinco e o chumbo concentraram-se, principalmente, nas raízes das plantas, e o cádmio se concentrou na parte aérea. Pelas características apresentadas nos solos estudados e pelas concentrações fitotóxicas do chumbo e do cádmio encontradas nas plantas desenvolvidas sobre o horizonte $B$ do Latossolo, não é recomendável a utilização desse resíduo como fonte de zinco para a cultura do arroz.

Palavras-chave: metais pesados, poluição, descarte.

\section{ABSTRACT}

The effects of application of siderurgical residue, originated from the zinc concentration in siderurgical high-ovens mud, as supply of zinc for rice plants (Oryza sativa L.) and the toxicity due to cadmium and lead from the residue, were studied in a greenhouse experiment.The period of the experiment was from April of 2005 to March of 2006. The soil materials were from the A and B horizons of a Yellow - Red Oxisol, and the A horizon of an Entisol, from Pinheiral municipality, State of Rio de Janeiro, and the rice (Oryza sativa $\mathbf{L}$.) variety utilized was the "BRS Curinga". There were applied four dosages of residue (94; 281; 844 and $2531 \mathrm{~kg} \mathrm{ha}^{-1}$ ) plus the testimony, without residue. The amount of zinc, cadmium and lead was determined in the root and aerial part of the rice plants. The plants cultivated in the A horizon of the Entisol presented the biggest dry biomass production, the highest zinc accumulation, and the smallest cadmium level. The plants cultivated in the Oxisol B horizon had the smallest dry biomass production, lowest zinc accumulation, and the highest level of lead. As for the Oxisol A horizon, the rice plants showed a good dry biomass production. The zinc and lead concentrated, mainly, in the roots; and cadmium in the aerial part. Based on the characteristics of the studied soils, and the fitotoxicity by lead showed in the rice plants grown on the Oxisol B horizon, the application of the siderurgical residue, is not recommended, as a zinc source for the rice crop.

Key words: heavy metals, pollution, recycling.

\section{INTRODUÇÃO}

O elevado volume de resíduos gerados na siderurgia faz com que esse tipo de atividade industrial mantenha-se em permanente busca de destinos que possibilite minimizar o impacto ambiental negativo e o custo. Entre os destinos que são dados aos resíduos siderúrgicos estão: a reciclagem, que se dá principalmente na refusão de sucatas metálicas nos

'Companhia Siderúrgica Nacional (CSN), Rua 21, nº 10, Volta Redonda, RJ, Brasil.

"Departamento de Solos, Universidade Federal Rural do Rio de Janeiro (UFRRJ), 23890-000, Seropédica, RJ, Brasil.

E-mail: nelmoura@ufrrj.br.*Autor para correspondência. 
fornos de aciaria e na utilização dos pós e das lamas na sinterização sendo este um processo de aglomeração a quente que existe dentro das usinas integradas. A venda é o destino dado para o resíduo mais volumoso na siderurgia, sendo que as escórias, são vendidas para indústrias de cimento, pavimentação e uso agrícola. Por fim, o menos interessante tanto para o meio ambiente como para a indústria, é depositado em aterros. Assim sendo, o uso destes resíduos como fonte de nutrientes na agricultura é uma maneira de reduzir o volume a ser disposto em solos (aterros) que, além de ser custosa, cria passivos ambientais. A aplicação de resíduos no solo com finalidades agrícolas, no entanto, requer um estudo meticuloso de modo a atender não só a legislação ambiental vigente, evitando, dessa forma, a poluição de áreas produtivas, como também a regulamentação que limita a concentração de poluentes nos alimentos, pois um dos grandes problemas para o uso agrícola de resíduos é a presença de metais pesados que, conforme a concentração, pode ser fitotóxica ou entrar na cadeia trófica, causando problemas à saúde do homem e outros animais e a contaminação da água subterrânea. O resíduo siderúrgico proveniente da concentração de lama de altos-fornos siderúrgicos apresenta elevadas concentrações de zinco (3,1\%), o que originou a proposta de utilizá-lo como fonte desse micronutriente para as plantas, uso que apresenta demanda pelo mercado (FAVARIN \& MARINI, 2000). Entretanto, outros metais pesados são normalmente encontrados no processo siderúrgico, entre eles o chumbo e o cádmio. Na maioria das seqüências de seletividade apresentadas para metais pesados em solos intemperizados, o $\mathrm{Pb}$ e o $\mathrm{Cu}$ são os mais fortemente adsorvidos e o Cd o mais fracamente, apresentando, geralmente, maior mobilidade e biodisponibilidade (ARAÚJO et al., 2002). O objetivo deste trabalho foi avaliar a absorção e a translocação de Zn, Cd e Pb pela cultura de arroz cultivado em solos que receberam o resíduo concentrado de lama dos altos fornos da Companhia Siderúrgica Nacional-CSN.

\section{MATERIAL E MÉTODOS}

O resíduo foi analisado dentro da legislação ambiental vigente, segundo a Norma 10004 (ABNT, 2005) para sua classificação, e também com vistas à sua utilização como fonte de zinco. As concentrações de cádmio e chumbo no ensaio de lixiviação foram de 0,74 e $12,8 \mathrm{mg} \mathrm{L}^{-1}$, respectivamente, estando acima do limite máximo permitido de 0,5 e 1,0 $\mathrm{mg} \mathrm{L}^{-1}$. Dessa forma, o resíduo foi classificado como Classe I, segundo Norma 10004 da ABNT. A concentração total no resíduo (em mg kg${ }^{-1}$ ) foi de: $\mathrm{Zn}=31060$; $\mathrm{Cd}=500 ; \mathrm{Pb}=15960$; $\mathrm{Fe}=14.7200 ; \mathrm{Mn}=6.150 ; \mathrm{Cu}=50 ; \mathrm{Cr}=10, \mathrm{eAl}=14.380$. Os materiais de solo utilizados foram provenientes de duas classes de solo, coletadas no município de Pinheiral (RJ) e classificadas como Latossolo Vermelho Amarelo e Neossolo Flúvico. Do primeiro, foram coletadas amostras dos horizontes A (LVAa) e B (LVAb) e do segundo (RU), os primeiros $20 \mathrm{~cm}$. As características físicas e químicas das amostras de terra foram determinadas conforme EMBRAPA (1997) e os resultados estão apresentados na tabela 1 .

A utilização dos horizontes mencionados deveu-se ao interesse de se avaliar a influência das diferentes características dos substratos face à dinâmica dos metais estudados. O experimento foi conduzido em casa de vegetação do campus da Universidade Federal Rural do Rio de Janeiro (UFRRJ), o qual se localiza no município de Seropédica - RJ ( $22^{\circ} 47^{\prime}$ de latitude sul e $43^{\circ} 40^{\prime}$ de longitude oeste) a aproximadamente $60 \mathrm{~km}$ da cidade do Rio de Janeiro, RJ. As amostras de solos utilizadas no experimento foram secas ao ar e peneiradas em tamis de malha de 4,0mm, sendo que as unidades que receberam o resíduo tiveram os mesmos misturados, manualmente, com o solo. As unidades experimentais foram constituídas por vasilhames plásticos de 5L, sem drenagem, contendo 4kg de terra - LVAa; LVAb e, RU.

Foram testadas quatro doses de resíduos (base seca) equivalentes a: 94; 281; 844 e $2531 \mathrm{~kg}$

Tabela 1 - Características químicas e físicas das amostras dos solos utilizadas.

\begin{tabular}{|c|c|c|c|c|c|c|c|c|c|c|c|c|c|c|c|c|c|c|c|}
\hline \multirow{2}{*}{ Solo } & \multirow{2}{*}{ Prof. } & \multirow{2}{*}{$\mathrm{pH}$} & \multirow{2}{*}{$\mathrm{Ca}^{2}$} & \multirow{2}{*}{$\mathrm{Mg}^{2+}$} & \multirow{2}{*}{$\mathrm{H}+\mathrm{Al}$} & \multirow{2}{*}{$\mathrm{Al}^{3+}$} & \multirow{2}{*}{ S } & \multirow{2}{*}{$\mathrm{T}$} & \multirow{2}{*}{$\mathrm{V}$} & \multirow{2}{*}{$\mathrm{P}$} & \multirow{2}{*}{ K } & \multirow{2}{*}{$\mathrm{C}$} & \multirow{2}{*}{$\mathrm{Zn}$} & \multirow{2}{*}{$\mathrm{Cd}$} & \multirow{2}{*}{$\mathrm{Pb}$} & \multirow{2}{*}{ Dens. } & \multicolumn{3}{|c|}{ Granulometria } \\
\hline & & & & & & & & & & & & & & & & & Areia & Silte & Argila \\
\hline & $\mathrm{cm}$ & & \multicolumn{4}{|c|}{----- $\mathrm{cmol}_{\mathrm{c}}\left(\mathrm{dm}^{3}\right)^{-1}-{ }^{-----}$} & \multicolumn{3}{|c|}{------\%------ } & \multicolumn{2}{|c|}{$\mathrm{mg} \mathrm{kg}^{-1}$} & $\mathrm{~g} \mathrm{~kg}^{-1}$ & \multicolumn{3}{|c|}{------mg kg ${ }^{-1}$------ } & $\mathrm{cm}^{-3}$ & \multicolumn{3}{|c|}{---------g kg-1--------- } \\
\hline LVAa & $0-20$ & 5,6 & 1,2 & 1,3 & 7,1 & 1,2 & 2,6 & 9,7 & 26 & 5 & 56 & 22,5 & 15,8 & nd & 12 & 1,03 & 470 & 100 & 430 \\
\hline LVAb & $30-50$ & 4,9 & 0,6 & 0,1 & 5,6 & 1,9 & 0,7 & 7,3 & 10 & 1 & 11 & 7,6 & 9,9 & nd & 13 & 1,18 & 370 & 60 & 570 \\
\hline RU & $0-20$ & 5,5 & 3,2 & 2,4 & 3,3 & 0,0 & 6,0 & 9,3 & 74 & 52 & 136 & 8,9 & 79,0 & nd & 21,7 & 1,14 & 658 & 166 & 176 \\
\hline
\end{tabular}

pH em água (1:2,5); Ca e Mg, H+Al - extraídos em $\mathrm{KCl} 1 \mathrm{~N}$; Al - extraído em acetato de cálcio 1N a pH 7,0, P - extraído com solução Carolina do Norte, K - extraído com dicromato de potássio $1 \mathrm{~N}$; C - Walkley - Black.

Ciência Rural, v.38, n.7, out, 2008. 
resíduo ha-1 ${ }^{-1}$ o que significou a adição de $3 ; 9 ; 27$ e $81 \mathrm{~kg} \mathrm{Zn} \mathrm{ha}^{-1}$; 1,6; 4,8; 14,4 e 43,2kg Pb ha-1 , e de 0,05; 0,$15 ; 0,45$ e $1,35 \mathrm{~kg} \mathrm{Cd} \mathrm{ha}^{-1}$. Os valores contidos entre a segunda e a terceira dose apresentam teores de zinco próximos às necessidades qüinqüenais de algumas culturas e o mais concentrado é um valor de zinco considerado fitotóxico para certas culturas (FAGERIA, 2000). O experimento utilizou o arroz (Oryza sativa, L.) por ser uma planta responsiva à adição de zinco (LOPES, 1998; FAGERIA, 2000) em unidades experimentais que seguiram o delineamento de blocos ao acaso, com quatro repetições, em um sistema $3 \times 5 \times 4$, com cultivo da variedade BRS Curinga. Após a incubação com o resíduo por 10 dias, foi feita a semeadura com arroz da variedade Curinga, mantendo-se quatro plantas de arroz por vaso. Durante todo o desenvolvimento do experimento, buscou-se manter os vasos com umidade próxima a $80 \%$ da capacidade de campo (CC). Os nutrientes e suas quantidades aplicadas aos vasos encontram-se na tabela 2. As folhas, os colmos e as raízes foram removidos para análise. As amostras foram lavadas em água de torneira e, posteriormente, em água deionizada. Elas foram deixadas para secagem em temperatura ambiente por dois dias e, posteriormente, secas em estufa a temperatura de $70^{\circ} \mathrm{C}$ até atingirem peso constante. O material para digestão foi obtido após moagem tanto das folhas e dos colmos como das raízes, em moinho tipo Willey com malha de $2 \mathrm{~mm}$. A moagem dos grãos foi realizada após remoção da pálea e da lema feita em gral de cerâmica. Utilizou-se o método de digestão proposto por TEDESCO et al. (1995) com ácido nítrico (65\%) e perclórico (85\%) na proporção 2:1 com $5 \mathrm{~mL}$ para cada $0,25 \mathrm{~g}$ de amostra analisada. O extrato resultante foi filtrado e analisado para determinação dos teores de zinco, chumbo e cádmio por espectrofotometria de absorção atômica com chama em aparelho VARIAN-AA600 com LD (mg kg-1) de 0,25para Cd, 0,10 para $\mathrm{Pb}$ e 0,20 para Zn, e LQ (mg kg ${ }^{-1}$ ) de 0,5 para Cd, 0,5 para $\mathrm{Pb}$ e 0,7 para $\mathrm{Zn}$. Foi utilizado o teste de Tukey a $5 \%$ como procedimento para comparação das médias obtidas. O programa Excel 7.0 foi utilizado para determinação de equações de regressão e suas respectivas curvas e $\mathrm{r}^{2}$, sendo as análises de significância executadas utilizando o programa SAEG, versão 5.0, desenvolvido por EUCLYDES(1983).

\section{RESULTADOS E DISCUSSÃO}

As concentrações mais elevadas de $\mathrm{Zn}$ foram verificadas nas raízes, comparativamente à parte aérea das plantas cultivadas nos dos três solos (Figura 1). A planta utilizada, provavelmente, apresentou algum mecanismo de restrição à transferência de zinco para a parte aérea. BONNECARRÈRE et al. (2004) mencionam a tendência do zinco de se acumular nas raízes, principalmente, quando absorvido em grandes quantidades. OLIVEIRA et al. (2005), trabalhando com lodo de esgoto contaminado com zinco, mencionam, também, uma menor translocação de zinco da raiz para parte aérea e desta para os grãos de arroz. A concentração de zinco considerada tóxica nas folhas de arroz é de $673 \mathrm{mg} \mathrm{kg}^{-1}$ na matéria seca (FAGERIA, 2000). A concentração de zinco observada, na maior dose, nas plantas desenvolvidas no solo LVAb, foi de, aproximadamente, $1000 \mathrm{mg} \mathrm{kg}^{-1}$ (Figura 1b), valor três vezes superior ao encontrado na folha das plantas de arroz cultivadas no LVAa e RU (Figura 1b). Essas concentrações elevadas podem ter contribuído para a fitotoxicidade nas plantas de arroz, dessa forma, explicando, parcialmente, a redução da matéria seca total observada na maior dose do resíduo nas plantas cultivadas em LVAb comparativamente aos outros dois solos (Figura 2).

As menores concentrações de zinco observadas nas plantas cultivadas nos solos LVAa e RU podem ter sido causadas pela diluição provocada pela maior produção de matéria seca total observada nesses solos (Figura 2). Esses resultados podem ser

Tabela 2 - Quantidade adicionada ( $\mathrm{mg} \mathrm{kg}^{-1}$ solo) e fonte dos nutrientes.

\begin{tabular}{|c|c|c|c|c|}
\hline \multirow{2}{*}{ Nutriente } & \multicolumn{2}{|c|}{-----------------------1ª dose*-------------------- } & \multicolumn{2}{|c|}{ - } \\
\hline & Quantidade & Fonte & Quantidade & Fonte \\
\hline $\mathrm{N}$ & 295 & $\mathrm{NH}_{4} \mathrm{NO}_{3}$ & 100 & $\mathrm{NH}_{4} \mathrm{NO}_{3}$ \\
\hline $\mathrm{P}$ & 370 & $\mathrm{KH}_{2} \mathrm{PO}_{4}$ & - & - \\
\hline K & 84 & $\mathrm{KH}_{2} \mathrm{PO}_{4}$ & 84 & $\mathrm{KCl}$ \\
\hline $\mathrm{Mg}$ & 15 & $\mathrm{MgSO}_{4}$ & 15 & $\mathrm{MgSO}_{4}$ \\
\hline $\mathrm{Ca}$ & - & - & 60 & $\mathrm{CaCl}_{2}$ \\
\hline
\end{tabular}

*7 dias antes da semeadura.

** 60 dias após semeadura (emissão floral). 

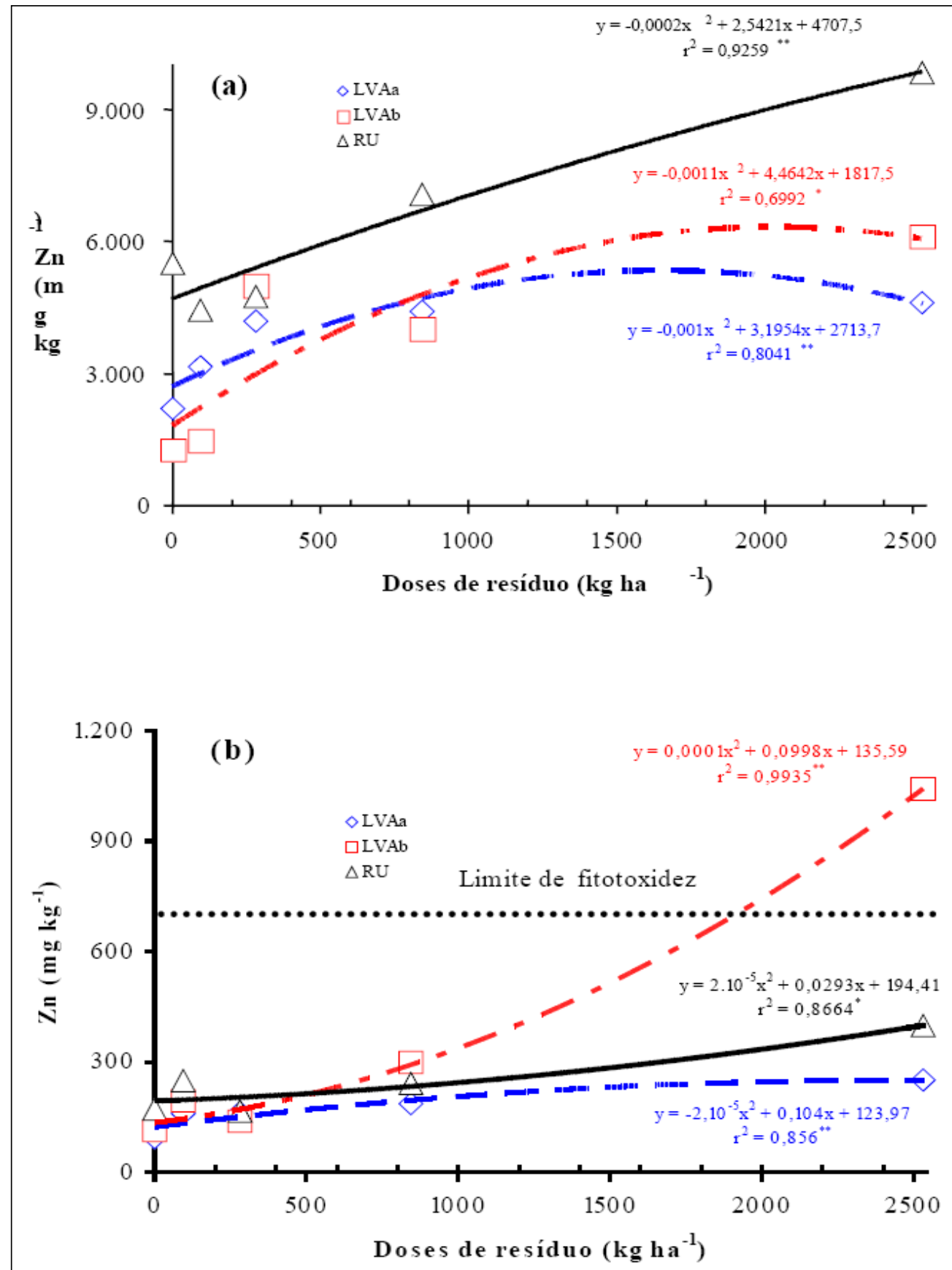

Figura 1 - Concentração de zinco na raiz (a) e parte aérea (b) em plantas de arroz (Oryza sativa L.) BRS Curinga cultivadas nos solos LVAa; LVAb e RU tratados com resíduo siderúrgico. LVAa = Latossolo Vermelho Amarelo horizonte A, LVAb= Latossolo Vermelho Amarelo, horizonte B RU= Neossolo Flúvico.

$*$ significativo a $5 \%$.

confirmados pela maior quantidade de zinco acumulada nas plantas de arroz desenvolvidas sobre o solo RU, que foi mais do que o dobro do acumulado nas plantas de arroz desenvolvidas sobre LVAb, conforme pode ser verificado na figura 3 . As raízes e a parte aérea das plantas de arroz desenvolvidas nos solos LVAa e RU apresentaram concentrações de chumbo que pouco variaram com o aumento da dose de resíduo aplicada (Figura 4). Nestes solos a produção de biomassa foi maior, porém, com acúmulo menor de $\mathrm{Pb}$ no tecido 


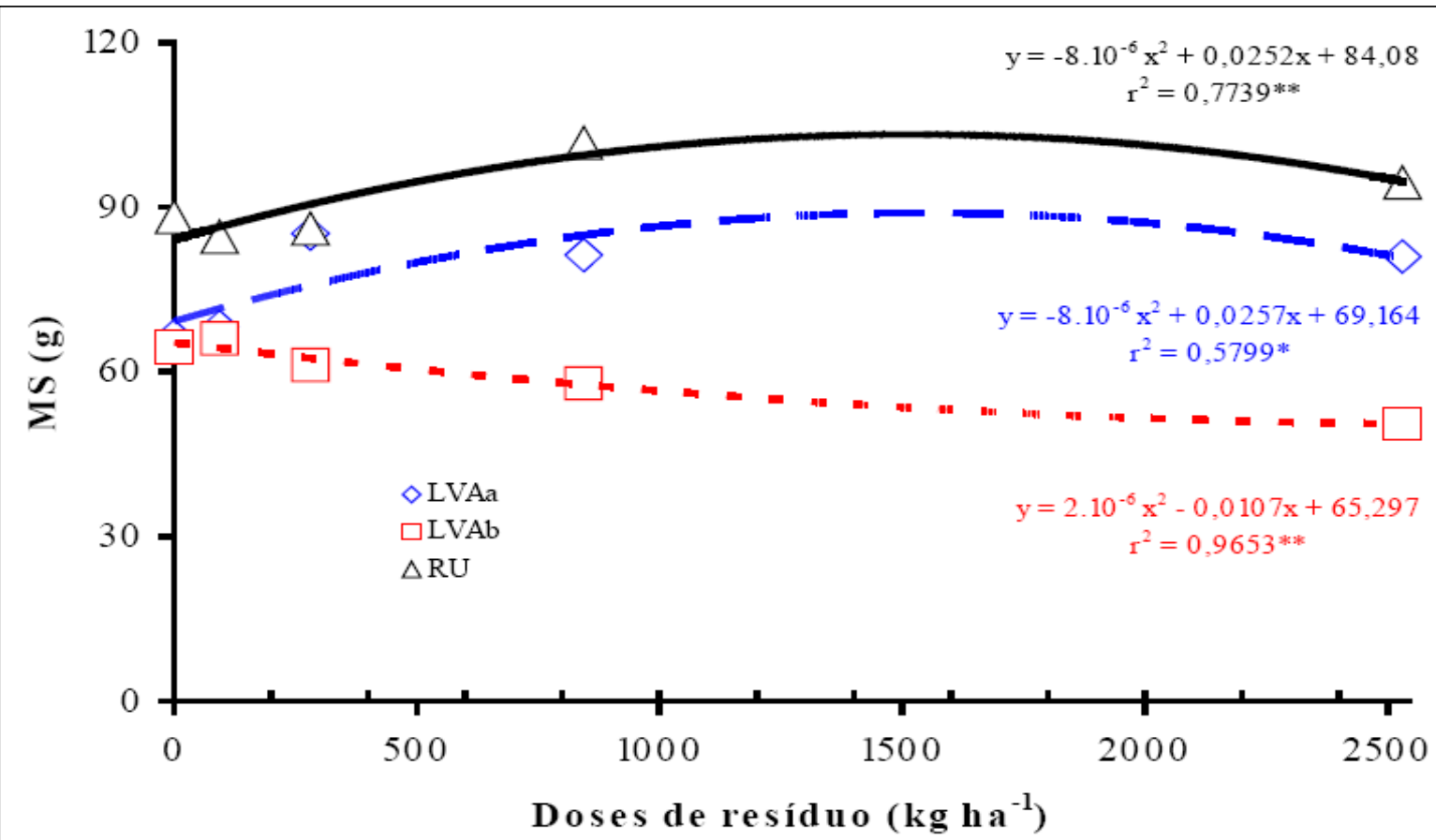

Figura 2 - Produção de matéria seca (MS) total (raiz+parte aérea+grão) em plantas de arroz (Oryza sativa L.) BRS Curinga cultivadas nos solos LVAa; LVAb e RU tratados com resíduo siderúrgico. LVAa = Latossolo Vermelho Amarelo horizonte A, LVAb= Latossolo Vermelho Amarelo, horizonte B RU= Neossolo Flúvico. *significativo a $5 \%$

vegetal (Figura 3), em razão da provável menor biodisponibilidade desse metal nesses solos.

A solubilidade do chumbo aumenta com a redução do pH(OLIVEIRA et al, 2005), o que explica as concentrações mais elevadas desse elemento na raiz e na parte aérea das plantas desenvolvidas sobre o solo LVAb (Figura 4). A massa de chumbo acumulada nas plantas (Figura 3) também foi mais elevada neste solo (na média três vezes superior ao das plantas do RU e quase oito vezes o das plantas do LVAa), razão direta da sua maior acidez (maior biodisponibilidade deste metal nesse solo). Este acúmulo crescente de chumbo, também, contribuiu, provavelmente, à fitotoxicidade apresentada nas plantas crescidas no solo LVAb, tendo causado redução de produção de matéria seca total em mais de 20\% (Figura 2). Segundo FAGERIA(2000), a redução da produção em torno de $10 \%$ é uma característica de fitotoxicidade.

Características do solo como o pH e a Capacidade de Troca Catiônica afetam a disponibilidade e a absorção do chumbo pelas plantas SHARMA \& DUBEY (2005). BORGES \& COUTINHO (2004), relataram a diminuição na absorção de $\mathrm{Pb}$ por plantas com o aumento do $\mathrm{pH}$ do solo (como verificado nos solos LVAa e RU) e do teor de matéria orgânica (como verificado no LVAa). De acordo com esses autores, o íon $\mathrm{Pb}^{2+}$ pode formar complexos com compostos húmicos do solo e o aumento de valor de $\mathrm{pH}$ do solo eleva, provavelmente, a capacidade da matéria orgânica em complexar o metal.

Como se pode observar na figura 5 , as concentrações de cádmio nas raízes e nas folhas foram, também, elevadas e semelhantes nos solos LVAa e RU, aumentando com a dose aplicada e sendo maior nas plantas desenvolvidas no solo LVAb (principalmente na maior dose do resíduo), possivelmente, também participando da fitotoxicidade, caracterizada pela redução de matéria seca nesse solo (Figura 2). Na maior dose, as plantas de arroz desenvolvidas no solo LVAb apresentaram um valor duas vezes maior que o considerado fitotóxico (FAQUIN, 2001). Nesse solo, nas menores doses, o baixo teor de zinco (oito vezes inferior ao do solo RU) possivelmente contribuiu para o aumento da absorção de cádmio pelas raízes, pois, conforme cita FAQUIN (2001), ocorre uma competição entre o zinco e o cádmio na absorção pelas plantas. $\mathrm{O}$ Cálcio e o fósforo presentes em maior concentração no RU, seguido do LVAa, (Tabela 1), possivelmente, interagem com o cádmio de forma a diminuir sua atividade na planta de acordo com ALLOWAY (1995) e 

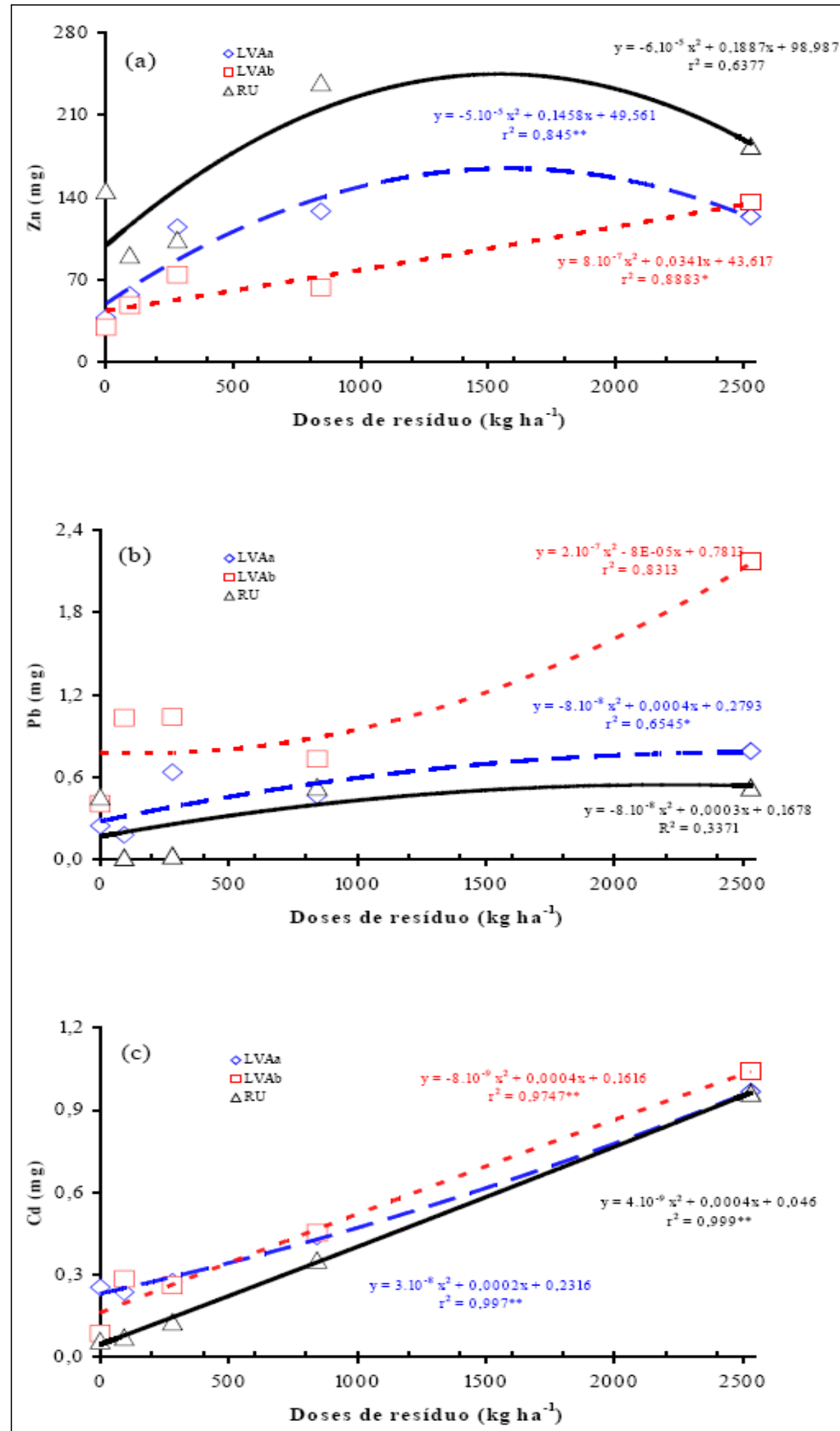

Figura 3 - Acumulação de zinco (a), chumbo (b), e de cádmio (c) em plantas de arroz cultivadas nos solos LVAa; LVAb e RU tratados com resíduo siderúrgico. LVAa = Latossolo Vermelho Amarelo horizonte A, LVAb= Latossolo Vermelho Amarelo, horizonte B RU= Neossolo Flúvico.

*significativo a $5 \%$

Ciência Rural, v.38, n.7, out, 2008. 

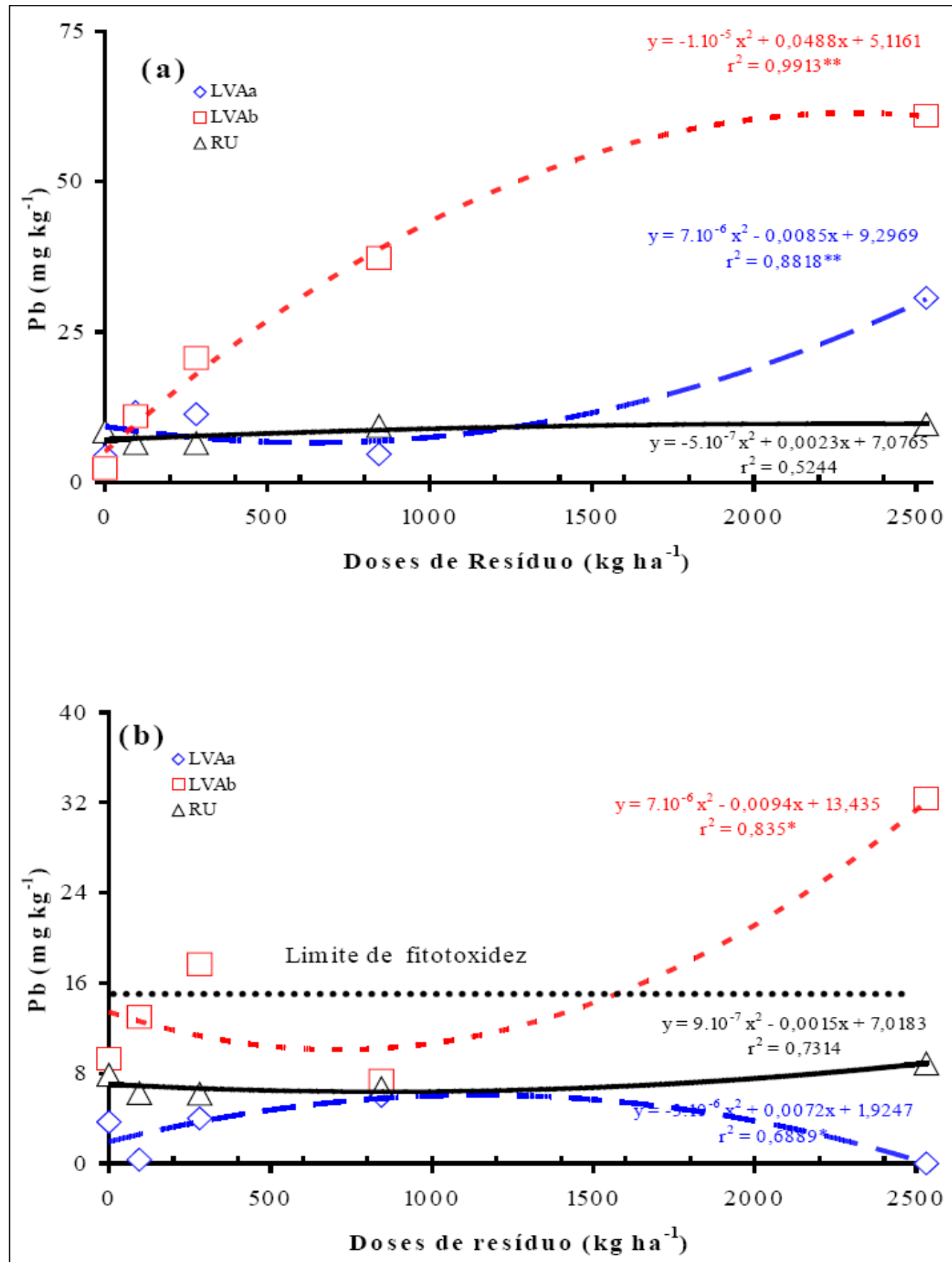

Figura 4 - Concentração de chumbo na raiz (a) e parte aérea (b) em plantas de arroz cultivadas nos solos LVAa; LVAb e RU tratados com resíduo siderúrgico. LVAa = Latossolo Vermelho Amarelo horizonte A, $\mathrm{LVAb}=$ Latossolo Vermelho Amarelo, horizonte B RU= Neossolo Flúvico.

*significativo a $5 \%$

OLIVEIRA et al. (2005). ALLOWAY (1995) menciona a competição de cálcio com o cádmio, reduzindo a absorção deste último pelas plantas. A massa total de cádmio absorvida pelas plantas de arroz (média de todos os tratamentos) foi semelhante nos solos estudados (Figura 3).

\section{CONCLUSÕES}

O resíduo siderúrgico utilizado não foi eficiente como fornecedor de zinco para a cultura de arroz desenvolvida em solos com pH superior a 5,5. Houve um maior acúmulo de zinco e de chumbo nas 

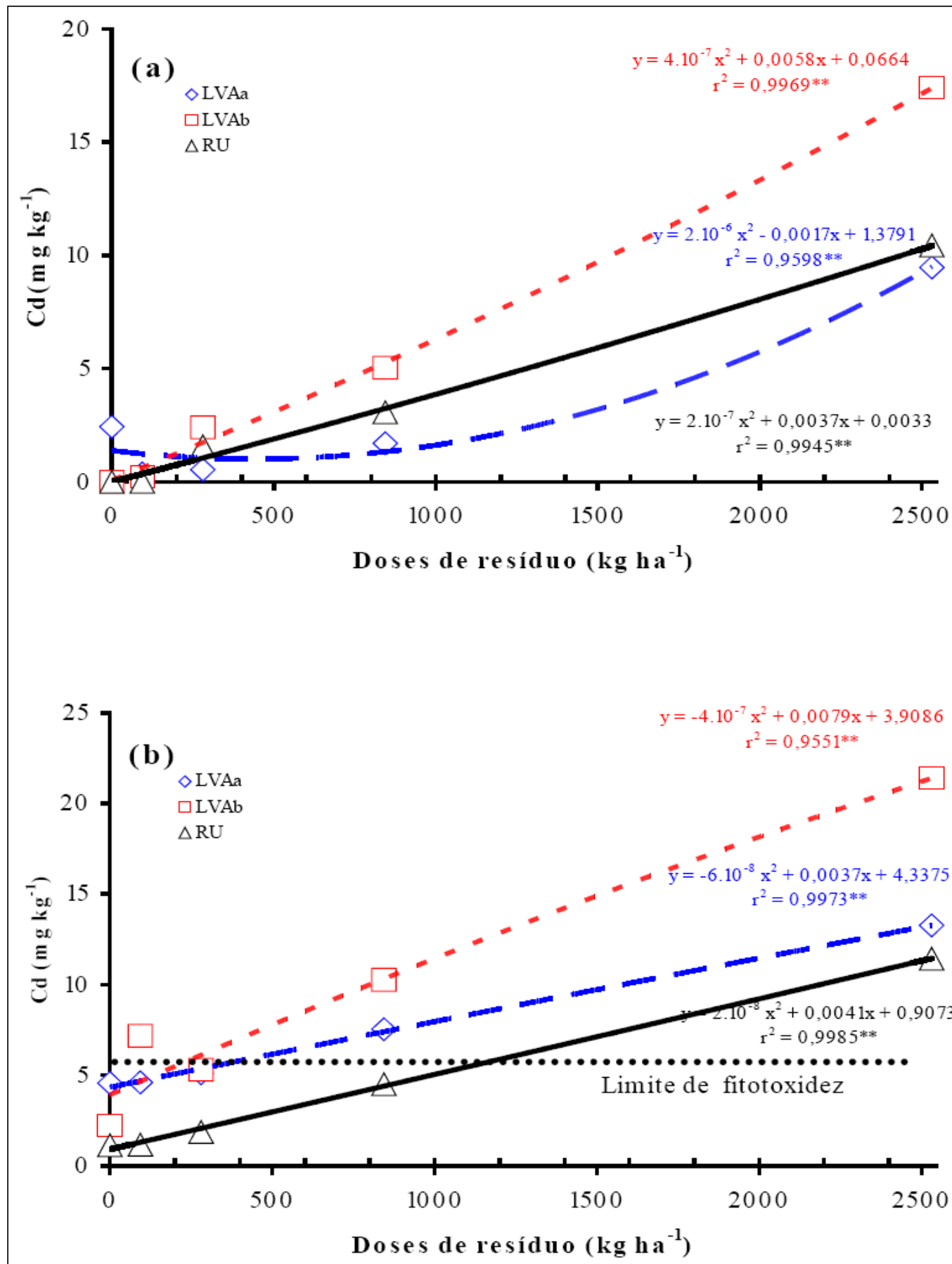

Figura 5 - Concentração de cádmio na raiz (a) e parte aérea (b) em plantas de arroz cultivadas nos solos LVAa; LVAb e RU tratados com resíduo siderúrgico. LVAa = Latossolo Vermelho Amarelo horizonte A, LVAb= Latossolo Vermelho Amarelo, horizonte B RU= Neossolo Flúvico *significativo a $5 \%$

raízes da planta, enquanto o cádmio concentrou-se na parte aérea. As plantas cultivadas no solo mais ácido (LVAb) apresentaram, na maior dose do resíduo aplicado, valores de zinco, chumbo e de cádmio acima do considerado fitotóxico. Pelas características apresentadas nos solos estudados e pelas concentrações fitotóxicas do chumbo e do cádmio encontradas nas plantas desenvolvidas sobre o horizonte $\mathrm{B}$ do Latossolo, não é recomendável a

Ciência Rural, v.38, n.7, out, 2008. 
utilização desse resíduo como fonte de zinco para a cultura do arroz.

\section{REFERÊNCIAS}

AY, B.J. Heavy metals in soils. 2.ed. London: Blackie A \& P, 1995. 386p.

ARAUJO, W.S. et al. Relação entre adsorção de metais pesados e atributos químicos e físicos de classes de solo do Brasil. Revista Brasileira de Ciência do Solo, v.26, p.17-27, 2002.

ASSOCIAÇÃO BRASILEIRA DE NORMAS TÉCNICAS. NBR-10004: Classificação de resíduos. Rio de Janeiro, 2005. 71p.

BONNECARRÈRE, R.A.G. et al. Resposta de genótipos de arroz irrigado à aplicação de zinco. Revista da Faculdade de Zootecnia, Veterinária e Agronomia, v.10. p.214-222, 2004.

BORGES, M.R.; COUTINHO E.L.M. Metais pesados do solo após aplicação de biossólido. II - Disponibilidade. Revista Brasileira de Ciência do Solo, v.28 n.3, p.557-568, 2004.

EMPRESA BRASILEIRA DE PESQUISA AGROPECUÁRIA EMBRAPA. Manual de métodos de análises de solos. 2.ed. Rio de Janeiro: EMBRAPA/CNPS, 1997. 214p.

EUCLYDES, R.F. Manual de utilização do programa SAEG (Sistema para análises estatísticas e genéricas). Viçosa, MG: UFV, 1983. 59p.
FAGERIA, N.K. Níveis adequados e tóxicos de zinco na produção de arroz, feijão, milho, soja e trigo em solo de Cerrado. Revista Brasileira de Engenharia Agrícola e Ambiental, v.4, n.3, p.390-395, 2000.

FAQUIN, V. Nutrição mineral de plantas. Textos acadêmicos. Lavras, MG: Ufla/Faepe, 2001. 182p.

FAVARIN, J.L.; MARINI, J.P. Importância dos micronutrientes para a produção de grãos. 2000. Acesso em abril de 2006. On line. Dipnível em: http:// www.snagricultura.org.br/artigos/artitec-micronutrientes.htm.

LOPES, A.S. Manual internacional de fertilidade do solo. Associação brasileira para pesquisa da potassa e do fosfato. Piracicaba: POTAFOS, 1998. 177p.

MARQUES, V.S. Efeitos de zinco e cádmio em arroz (Oriza sativa L.) cultivado em solução nutritiva e em solo tratado com lodo de esgoto enriquecido. 1997. 146f. Dissertação (Mestrado em Ciência do Solo) - UFRRJ, Rio de Janeiro.

OLIVEIRA, C. et al. Efeitos da aplicação do lodo de esgoto enriquecido com cádmio e zinco na cultura do arroz. Revista Brasileira de Ciência do Solo v.29 n.1, p.109-116, 2005.

SHARMA, P.; DUBEY, R.S. Lead toxicity in plants. Brazilian Journal of Plant Physiology, v.17 n.1, p.35-52, 2005.

TEDESCO, M.J. et al. Análise de solo, plantas e outros materiais. 2.ed. Porto Alegre: Departamento de Solos, UFRGS, 1995. 174p. (Boletim técnico n.5). 